Combined therapy of ovarian cancer has a long history. It has been applied for many years. The first drug which was commonly combined with other chemotherapeutics was cisplatin. It turned out to be effective given together with alkylating agents as well as with taxanes. Another drug which is often the basis of first-line therapy is doxorubicin.

The use of traditional chemotherapy is often limited due to side effects. This is why new drugs, targeted specifically at cancer cells (e.g. monoclonal antibodies or epidermal growth factor receptor inhibitors), offer a welcome addition when used in combination with conventional anticancer agents. Drugs applied in combination should be synergistic or at least additive. To evaluate the type of interaction between drugs in a plausible sequence, isobolographic analysis is used. This method allows one to assess whether the two agents could make an efficient combination, which might im prove the therapy of ovarian cancer.

Key words: combined therapy, ovarian cancer, synergism, isobolographic analysis.

Contemp Oncol (Pozn) 2015; 19 (5): 350-353 DOI: $10.5114 /$ wo.2014.43975

\section{Two drugs are better than one. A short history of combined therapy of ovarian cancer}

\author{
Barbara Bukowska, Arkadiusz Gajek, Agnieszka Marczak
}

Department of Thermobiology, Institute of Biophysics, Faculty of Biology and Environmental Protection, University of Lodz, Lodz, Poland

\section{Introduction}

Drug combinations have been used for treating diseases for many years. There are many advantages of using drug combinations. First of all is the possible increase of efficacy of the therapeutic effect, especially when drugs in sequence differ in their mechanism of action, but give similar effects. Secondly, using drug regimens allows decreasing dosages of each component and thus their toxicity, which results in less severe adverse effects of each. The third reason is minimizing the development of drug resistance, which is a big challenge for modern medicine and very often is the most important limitation and a problem difficult to avoid, especially in cancer and bacterial infections' treatment [1].

However, there are different types of interactions between two or more substances given simultaneously and not all of them are clinically useful. The most desirable is synergism. This type of interaction occurs when the effect of drugs in a combination is much higher than would be expected from the individual activities of each component [2]. Less efficient are medicines which act additively. In this situation the final activity of a sequence is the simple sum of the activities of each agent. The third type of drug interaction is antagonism, when the combination is less potent than would be predicted from the individual potency of each component [2].

Clinical practice has shown which sequences are the most efficient in particular types of cancer. But it can also be evaluated mathematically using isobolographic analysis which was first introduced by Loewe in the 1920 s [3]. The isobologram is constructed by evaluating the two $\mathrm{EC}_{50}$ values for each drug (given alone) and plotted along different axes of a coordinate system. The two obtained points on $x$ - and $y$-axes are then connected by a straight line (line of addition) [4]. The $E C_{50}$ values for drugs in sequence are then determined and plotted on the same graph. The points lying on the line of addition correspond to the simple addition of the used combination. If the points are under the line of addition, the combination is synergistic. It means that the activity of the combination is greater than that expected from the activities of the two drugs given separately. If the points are above the line of addition, drugs in the combination act antagonistically. Figure 1 shows those relations. Mathematically the line of simple addition is given by the following equation:

$$
\frac{a}{A}+\frac{b}{B}=\gamma
$$

where $A$ and $B$ are the doses of agents $A$ and $B$ respectively, which, when administered alone, give the specified effect. $a$ and $b$ are the doses of $A$ and $B$ in combination that produce this level of effect. If $\gamma=1$, the combination is additive; if $\gamma>1$, it is antagonistic; and if $\gamma<1$, it is synergistic [4]. 


\section{The beginnings of combined therapy in ovarian cancer treatment}

Combined therapy is widely applied in ovarian cancer treatment. The first combination which turned out to be efficient in this type of cancer was cisplatin or carboplatin combined with an alkylating agent - usually cyclophosphamide [5]. Those two drugs differ in the mechanism of action, which is why their combination appeared to be effective. Cisplatin is a cycle-specific and phase-non-specific antineoplastic drug. However, it is most effective during the S-phase of the cell cycle. It binds to DNA and causes crosslinking of DNA, which results in inhibiting gene transcription and DNA replication. The protein synthesis and cell proliferation is thereby blocked [6]. Cyclophosphamide, as an alkylating agent, adds an alkyl group to DNA. Due to its low toxicity and wide anticancer spectrum, it is the most often used alkylating agent, applied in the treatment of many different types of cancers [7].

In the mid-1990s this standard was modified. A trial performed by the Gynecologic Oncology Group proved that the combination of cisplatin and paclitaxel is much more effective compared with the previous regimen. Paclitaxel, as well as docetaxel, belongs to the taxanes. It was first isolated in the mid-1960s from the bark of Taxus brevifolia, but now it is obtained by a semi-synthetic route from the needles of Taxus baccata. Paclitaxel stabilizes microtubules and inhibits tubulin depolymerization, which results in dysregulation of the cell cycle. The consequence of mitotic failure is cell death [8].

In the trial mentioned above, almost 400 women took part. They were divided into two groups: one was treated with a cisplatin-cyclophosphamide combination, the other with a cisplatin-paclitaxel combination. Adverse effects, such as alopecia, neutropenia, fever and allergic reaction, were more common in the cisplatin-paclitaxel group. Progression-free survival as well as survival was significantly longer in the cisplatin-paclitaxel group. Those findings resulted in incorporating paclitaxel into the firstline therapy of ovarian cancer, which brought considerable improvement in the treatment of advanced ovarian cancer [9]. Besides cisplatin also carboplatin, which has the same mechanism of action, was combined with paclitaxel. Such trials are performed with the aim to find not only the most potent sequence, but also the most tolerable. That is why the cisplatin-paclitaxel combination (PT) was compared to the carboplatin-paclitaxel combination (TC) in women with advanced ovarian cancer (stage IIBIV). Both sequences appeared to be equally efficient, but the TC combination was associated with lower frequency of toxicity to the gastrointestinal tract and to the nervous system than the PT sequence. Those results showed that the carboplatin-paclitaxel regimen might be a good alternative to the cisplatin-paclitaxel combination, with similar activity, but better tolerability [10].

Paclitaxel was not the only taxane whose efficacy in combination with carboplatin was evaluated. Also the docetaxel-carboplatin regimen was tested and compared to the paclitaxel-carboplatin sequence activity. Although the progression-free survival was similar after both combi-

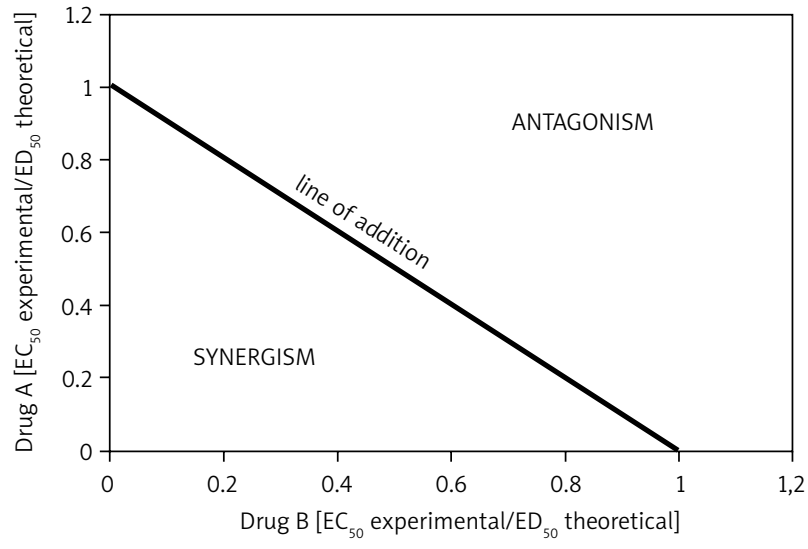

Fig. 1. Relations between drugs on isobologram

nations, docetaxel-carboplatin was related to higher neurotoxicity than paclitaxel-carboplatin. Also neutropenia was more significant, but this adverse effect did not influence patient safety. On the other hand, the quality of life was a little better after treatment with docetaxel. Those findings revealed that the docetaxel-cisplatin combination might be an alternative first-line chemotherapy sequence for women with ovarian cancer [11].

Another drug which is commonly used in the treatment of ovarian cancer in monotherapy as well as in combined therapy is doxorubicin. It has an intricate and pleiotropic mechanism of action, which includes intercalation to DNA, reactive oxygen species generation, topoisomerase I and II inhibition and induction of apoptosis [12, 13]. In particular, the pegylated liposomal form (PLD, Doxil ${ }^{\circledR}$ ) of this drug has been tested. When DOX is packed in a liposome coated with polyethylene glycol, cardiotoxicity of the drug is minimized and also pharmacokinetics is improved. Pujade-Lauraine et al. postulated that pegylated liposomal doxorubicin with carboplatin (CD) is more efficient than standard carboplatin and paclitaxel (CP) in patients with platinum-sensitive relapsed ovarian cancer. The group of women treated by CD combination lived longer than the second one. Also the adverse effects, such as alopecia, hypersensitivity reactions and sensory neuropathy, were more advanced after CP therapy. Only hand-foot syndrome and nausea were observed more often in the CD group [14]. The same results were obtained by Pignata et al. Carboplatin-pegylated liposomal doxorubicin combinations were effective in advanced ovarian cancer [15].

The efficacy of topotecan-doxorubicin combination was determined on three different ovarian cancer cell lines (ES-2, OVCAR-3 and SKOV-3) over extended time (1 to 72 hours). The results showed that this sequence was additive in the SKOV-3 cell line, but highly synergistic in the two other cell lines, and those interactions increased with time of exposure [16].

\section{Targeted therapy in combination with standard anticancer drugs}

Traditional methods of treatment such as conventional chemotherapy or surgery are often insufficient due to poor 
treatment results and side effects. That is why highly selective drugs are needed, which target cancer cells, avoiding the normal ones. One of the new approach in ovarian cancer treatment is targeted therapy, in which modulators of signal transmission are used. It results in dysregulation of cell proliferation and differentiation. Commonly applied substances are monoclonal antibodies (such as trastuzumab or bevacizumab) and small molecular tyrosine kinase inhibitors (erlotinib, gefitinib or cetuximab). The combination of such drugs with chemotherapy or radiotherapy improves treatment results. Appling substances which might block more than one metabolic pathway may enhance the anticancer therapy effectiveness [17].

A new drug whose effectiveness has been recently determined in the therapy of ovarian cancer is imatinib (Gleevec). It is a competitive tyrosine-kinase inhibitor. Its synergism in combination with paclitaxel and carboplatin has been proved. Mundhenke et al. demonstrated that imatinib reduced ovarian cancer cell growth and induced proapoptotic changes when it was used in monotherapy and in combination with other chemotherapeutic agents - paclitaxel and cisplatin [18]. Imatinib appeared to be active also in combination with docetaxel. Its efficacy was established by Matei et al. The results showed that the imatinib-docetaxel combination is potent and well tolerated in patients with advanced platinum-resistant ovarian cancer [19].

Another effective regimen for ovarian cancer treatment is paclitaxel combined with bevacizumab - an active angiogenesis inhibitor. Patients with heavily pretreated recurrent epithelial ovarian cancer who were treated with this combination suffered from similar adverse effects compared to those who were given only paclitaxel. However, progression-free survival and overall survival were longer in the group treated with the combination [20].

\section{Summary}

Combined anticancer therapy gives much better results than using single antineoplastic agents. However, it is still imperfect, and new, more effective regimens are required. One of them might be WP 631 (an anthracycline analogue) combined with epothilone B (a microtubule stabilizer). WP 631 is a member of a new class of bisanthracyclines; it contains two molecules of daunorubicin which are linked through p-xylenyl linker [21]. In comparison to monomeric forms its affinity to DNA binding is much higher. Recent studies have proved that WP 631 has higher efficacy than first generation anthracyclines. But, what is the most important, WP 631 has low affinity to cell membrane transporters which are responsible for removing drugs from the cells. Taken this into consideration, WP 631 gives hope for overcoming multidrug resistance [22].

Epothilones were discovered in 1987 as secondary metabolites of myxobacteria. Two 16-membered macrolides are obtained from the myxobacterium Sorangium cellulosum: epothilone A and B. Epothilones have a similar mechanism of actions as taxanes. They bind to a pharmacophore on the $\beta$-subunit of microtubules. In comparison to taxanes, epothilones inhibit in vitro growth of human cancer cells with overexpression of P-glycoprotein. Plausibly this group of drugs might be efficient in the treatment of multidrug-resistant cancers [23].

The antitumor activity of those two drugs - WP 631 and epothilone B (Epo B) - is well established. WP 631 is more efficient than DOX or DNR in some types of cancer cells, including Jurkat T lymphocytes [24], human non-small cell lung carcinoma cells (H1299) [25], chronic myelogenous leukemia cells (K562) [26], human ovarian cancer (SKOV-3) [27] and colon carcinoma cells (HCT116) [28]. Epothilone B is effective against human ovarian cancer cells (SKOV-3) [29]. They have different mechanisms of action - WP 631 mainly generates reactive oxygen species and intercalates to DNA, whereas Epo B stabilizes microtubules, but they induce a similar effect in cancer cells - growth inhibition. This might be a prerequisite for further studies on application of WP 631-Epo B combination in chemotherapy. If its effectiveness and potency will be proved, it could be a good alternative for currently used regimens - with higher activity, also against multidrug-resistant cancers, and less toxicity.

The authors declare no conflicts of interest. This work was supported by grant No. N N405 100939 of the Ministry of Science and Higher Education (Poland).

\section{References}

1. Chou TC. Theoretical basis, experimental design, and computerized simulation of synergism and antagonism in drug combination studies. Pharmacol Rev 2006; 58: 621-81.

2. Tallarida RJ. Interactions between drugs and occupied receptors. Pharmacol Ther 2007; 113: 197-209.

3. Loewe S. Die quantitativen probleme der pharmakologie. Ergebn Physiol 1928; 27: 47-87.

4. Gessner PK. Isobolografic analysis of interactions: an update on applications and utility. Toxicology 1995; 105: 161-79.

5. McGuire WP. Current status of taxane and platinum-based chemotherapy in ovarian cancer. J Clin Oncol 2003; 21: 133-5.

6. Karbownik A, Szałek E, Urjasz H, Głęboka A, Mierzwa E, Grześkowiak E. The physical and chemical stability of cisplatin (Teva) in concentrate and diluted in sodium chloride $0.9 \%$. Contemp Oncol (Pozn) 2012; 16: 435-9.

7. Iżycki D, Nawrocki S, Łaciak M, Gryska K, Baksalary-lżycka K, Mackiewicz A. Wpływ cyklofosfamidu na tumorogenność komórek czerniaka modyfikowanych genetycznie II-6 i Hyper-II-6. Contemp Oncol (Pozn) 2004; 8: 124-31.

8. Bodnar L, Wcisło G, Miedzińska-Maciejewska M, Szczylik C. Docetaksel i paklitaksel: porównanie ich budowy, farmakologii oraz mechanizmów oporności. Contemp Oncol (Pozn) 2004; 8: 435-46.

9. McGuire WP, Hoskins WJ, Brady MF, Kucera PR, Partridge EE, Look KY, Clarke-Pearson DL, Davidson M. Cyclophosphamide and cisplatin compared with paclitaxel and cisplatin in patients with stage III and stage IV ovarian cancer. N Engl J Med 1996; 334: 1-6.

10. du Bois A, Lück HJ, Meier W, et al. A randomized clinical trial of cisplatin/paclitaxel versus carboplatin/paclitaxel as first-line treatment of ovarian cancer. J Natl Cancer Inst 2003; 95: 1320-9.

11. Vasey PA, Jayson GC, Gordon A, et al. Phase III randomized trial of docetaxel-carboplatin versus paclitaxel-carboplatin as first-line chemotherapy for ovarian carcinoma. J Natl Cancer Inst 2004; 96: 1682-91.

12. Mutschler E. Antybiotyki działające cytostatycznie In: Farmakologia i toksykologia. Buczko W (ed.). Wydawnictwo MedPharm, Wrocław 2010; 971-3. 
13. Dragojew S, Marczak A, Maszewski J, Ilnicki K, Jóźwiak Z. The induction of apoptosis by daunorubicin and idarubicin in human trisomic and diabetic fibroblasts. Cell Mol Biol Lett 2008; 13: 182-94.

14. Pujade-Lauraine E, Wagner U, Aavall-Lundqvist E, et al. Pegylated liposomal doxorubicin and carboplatin compared with paclitaxel and carboplatin for patients with platinum-sensitive ovarian cancer in late relapse. J Clin Oncol 2010; 28: 3323-29.

15. Pignata S, Scambia G, Ferrandina G, et al. Carboplatin plus paclitaxel versus carboplatin plus pegylated liposomal doxorubicin as first-line treatment for patients with ovarian cancer: the MITO-2 randomized phase III trial. J Clin Oncol 2011; 29: 3628-35.

16. Patankar NA, Pritchard J, van Grinsven M, Osooly M, Bally MB. Topotecan and doxorubicin combination to treat recurrent ovarian cancer: the influence of drug exposure time and delivery systems to achieve optimum therapeutic activity. Clin Cancer Res 2013; 19 : 865-77.

17. Karczmarek-Borowska B, Trelińska-Nowosad T, Karolewski K, Jóźwik P. Leczenie celowane $\mathrm{W}$ raku jajnika - na jakim etapie jesteśmy? Contemp Oncol (Pozn) 2007; 11: 492-7.

18. Mundhenke C, Weigel MT, Sturner KH, et al. Novel treatment of ovarian cancer cell lines with imatinib mesylate combined with paclitaxel and carboplatin leads to receptor-mediated antiproliferative effects. J Cancer Res Clin Oncol 2008; 134: 1397-405.

19. Matei D, Emerson RE, Schilder J, et al. Imatinib mesylate in combination with docetaxel for the treatment of patients with ad vanced, platinum-resistant ovarian cancer and primary peritoneal carcinomatosis: a Hoosier Oncology Group trial. Cancer 2008; 113 723-32.

20. O'Malley DM, Richardson DL, Rheaume PS, et al. Addition of bevacizumab to weekly paclitaxel significantly improves progres sion-free survival in heavily pretreated recurrent epithelial ovarian cancer. Gynecol Oncol 2011; 121: 269-72.

21. Chaires JB, Leng F, Przewloka T, Fokt I, Ling YH, Perez-Soler R, Priebe $W$. Structure-based design of a new bisintercalating anthracycline antibiotic. J Med Chem 1997; 40: 261-6.

22. Brooks TA, O'Loughlin KL, Minderman H, et al. The 4'-O-benzylated doxorubicin analog WP744 overcomes resistance mediated by P-glycoprotein, multidrug resistance protein and breast cancer resistance protein in cell lines and acute myeloid leukemia cells. Invest New Drugs 2007; 25: 115-22.

23. Lee FY, Smykla R, Johnston K, et al. Preclinical efficacy spectrum and pharmacokinetics of ixabepilone. Cancer Chemother Pharmacol 2009; 63: 201-12.

24. Villamarin S, Ferrer-Miralles N, Mansilla S, Priebe W, Portugal Induction of G(2)/M arrest and inhibition of c-myc and p53 transcription by WP631 in Jurkat T lymphocytes. Biochem Pharmacol 2002; 63: 1251-8.

25. Ashikawa K, Shishodia S, Fokt I, Priebe W, Aggarwal BB. Evidence that activation of nuclear factor-kappaB is essential for the cytotoxic effects of doxorubicin and its analogues. Biochem Pharmacol 2004; 67: 353-64

26. Haj HT, Salerno M, Priebe W, Kozlowski H, Garnier-Suillerot A. New findings in the study on the intercalation of bisdaunorubicin and its monomeric analogues with naked and nucleus DNA. Chem Biol Interact 2003; 145: 349-58.

27. Rogalska A, Gajek A, Szwed M, Jóźwiak Z, Marczak A. The role of reactive oxygen species in WP 631-induced death of human ovarian cancer cells: A comparison with the effect of doxorubicin. Toxicol In Vitro 2011; 25: 1712-20.

28. Mansilla S, Bataller M, Portugal J. A nuclear budding mechanism in transiently arrested cells generates drug-sensitive and drug-resistant cells. Biochem Pharmacol 2009; 78: 123-32.

29. Rogalska A, Marczak A, Gajek A, Szwed M, Śliwińska A, Drzewoski J, Jóźwiak Z. Induction of apoptosis in human ovarian cancer cells by new anticancer compounds, epothilone $A$ and B. Toxicol In Vitro 2013; 27: 239-49.

\section{Address for correspondence}

Barbara Bukowska

Department of Thermobiology

Institute of Biophysics

Faculty of Biology and Environmental Protection

University of Lodz

Pomorska 141/143

90-236 Lodz, Poland

e-mail: barbara.bukowska@onet.pl

Submitted: 8.05.2013

Accepted: $\quad 18.12 .2013$ 